\title{
Study on Strength Characteristics of Cement-Solidified Bauxite Tailings Slime
}

\author{
Kai XU ${ }^{\mathrm{a}, \mathrm{b}, 1}$, Zhiqiang WU ${ }^{\mathrm{a}, \mathrm{b}}$, Zhihuan WANG ${ }^{\mathrm{c}}$, Jie REN ${ }^{\mathrm{b}}$ and Shuaiheng $\mathrm{LI}^{\mathrm{b}}$ \\ ${ }^{a}$ State Key Laboratory of Hydrology-Water Resources and Hydraulic Engineering, \\ Nanjing 210029, China \\ ${ }^{\mathrm{b}}$ Nanjing Hydraulic Research Institute, Nanjing 210029, China \\ 'Jiangsu Provincial Hydraulic Research Institute, Nanjing 210017, China
}

\begin{abstract}
The wet slime tailing pond formed during the production of accumulated bauxite is a source of artificial debris flow hazard with high potential energy. In order to explore the effectiveness of solidification technology in processing bauxite slime, experimental study was conducted on the strength characteristics of cement-solidified slime with bauxite slime as the test object, so as to investigate the impact of cement contents and curing ages on the compressive strength of cement-solidified slime. According to the test results, the strength and deformation characteristics of solidified slime are related to the cement content, and the higher the cement admixed amount, the greater the compressive strength of solidified slime; the cement-solidified slime samples are subject to brittle failure, and with the increase of strain, the stress first rises to its peak and then decreases rapidly. The findings may serve as reference in processing bauxite slime.
\end{abstract}

Keywords. Bauxite, tailings slime, strength characteristics, solidified

\section{Introduction}

Slime is the solid waste produced in the process of mining production. In Guangxi, Yunnan and other karst landform developed areas, the slurry in the pond permeates into underground karst caves, which will cause serious soil and groundwater pollution problems [1-2]. In this regard, many scholars have studied related technologies such as slime facilitation technology and rapid dehydration technology, and achieved certain results [3-8]. For example, Liu Yuanqing et al. introduced in detail the problems existing in iron tailings of Jinling Mine and the application of filter press in tailings dehydration treatment [9]. Qi Meichao et al. carried out an experimental study on the dehydration of slime by thickening in Zhangzhuang Mine, which proved that this method could effectively obtain tailings with moisture content lower than $20 \%$, which is beneficial to the reuse of slime [10-12]. Liu Chenggong et al. summarized the current representative tailings treatment methods, and introduced the effectiveness of the new technology combined with hydro cyclone and linear dewatering screen applied to the iron tailings pond of Shougang Group. The above researches have well developed the slime facilitation and dehydration technologies, but there are few reports on the application of solidification technology in the treatment of bauxite slime.

\footnotetext{
${ }^{1}$ Kai Xu, State Key Laboratory of Hydrology-Water Resources and Hydraulic Engineering, Nanjing 210029, China; E-mail: kxu@nhri.cn.
} 
To this end, experimental study was conducted for the strength characteristics of cement-solidified slime by taking the bauxite slime of Jiangwan Tailings Pond of Huayin Aluminium as the test object, so as to investigate the impact of cement contents and maintenance period on the compressive strength of cement-solidified slime. The findings may serve as reference in processing bauxite slime.

\section{Material and Test Method}

The tailings slurry utilized in the test was gathered from the thickening tank in Jiangwan Tailings Pond of Huayin Aluminium, with initial water content of about $280 \%$ and density of about $1.20 \mathrm{~g} / \mathrm{cm}^{3}$. After vacuum dehydration, the slurry bulk density was $1.67 \mathrm{~g} / \mathrm{cm}^{3}$ and the moisture content was about $60 \%$. Ordinary Portland cement used in the test was Type I Portland cement without any mixing materials, with strength grade of 42.5 .

Considering the influence of sample size on soil strength, cylindrical test specimens with a diameter of $39.1 \mathrm{~mm}$ and a height of $80 \mathrm{~mm}$ were selected in this test according to the standard sample size for unconfined compressive strength test in GB/T 50123-2019 Standard for geotechnical testing method. According to the natural moisture content and density conditions of the actual soil layer on site, the dry density of the sample was set as $1.3 \mathrm{~g} / \mathrm{cm}^{3}$ in this test, and the corresponding saturated moisture content was $40 \%$.

In order to ensure the uniformity and saturation state of cement-solidified soil samples, the specific sample preparation process was as follows: firstly, dry the slime taken from the site in the air outdoors, and then break up the soil mass and screen by a $1 \mathrm{~mm}$ sieve to remove impurities; afterwards, take a sufficient amount of soil samples according to the quartering method to measure the air-dried moisture content; finally, place the soil samples into a sealed glass jar. Before sample preparation, calculate the air-dried soil mass required in the test according to the designed dry density, and calculate the cement mass according to the cement content. When preparing samples, weigh the air-dried soil and cement required for preparing a sample according to the size of the sample and put them into a stainless-steel basin. After mixing evenly by hand, put the mixed cement soil into a glass jar. After all the samples in the same batch were mixed, take all the mixed cement soil out of the glass jar and put into JJ-5 planetary cement mortar mixer for mixing at a speed of $285 \mathrm{r} / \mathrm{min}$. After continuous mixing for $10 \mathrm{~min}$, the cement and soil were mixed evenly. When preparing the soil samples, apply a layer of vaseline evenly on the inside of the three valves in advance, then weigh a certain amount of mixed cement soil, and prepare the cement soil sample according to the layered sample preparation method; finally, place the three valves filled with samples in a saturation tank for air extraction to reach saturation. After soaking in water for 24 hours, take out the saturator from the saturation tank and dismantle it. After wrapping the samples with filter paper, put them into a saturated sand box for curing.

After the samples were cured to the design age, the strain-controlled automatic unconfined compressive strength meter for solidified soil of Nanjing Soil Instrument Factory Co., Ltd. was used for uniaxial compressive strength test.

In order to investigate the influence of curing agent dosage and curing age on the mechanical properties of solidified slime, 16 groups of unconfined compressive strength tests were conducted, with 3 parallel samples for each group, in which the 
cement dosage was $6.0 \%, 8.0 \%, 10.0 \%$ and $12.0 \%$, and the curing age varied between 7 days, 14 days 28 days and 90 days.

\section{Test Results}

\subsection{Stress and Strain Curves of Cement-Solidified Slime}

The stress and strain curves of samples with different cement admix amount and different curing ages are demonstrated in figure 1 to figure 4. According to the curves, when the curing age is 7 days, the axial stress of solidified slime samples with admixture amount of $6 \%, 8 \%, 10 \%$ and $12 \%$ increases with the increase of strain until to the peak, and then gradually decreases. The stress-strain curves of cement-solidified tailings samples show brittle failure under unconfined conditions. When the cement content is $6 \%$, the unconfined compressive strength of solidified slime samples is 420.2 $\mathrm{kPa}, 404.3 \mathrm{kPa}$ and $412.3 \mathrm{kPa}$ respectively, and the average compressive strength is $412.3 \mathrm{kPa}$. When the cement content is $8 \%$, the unconfined compressive strength of solidified slime samples is $644.5 \mathrm{kPa}, 703.1 \mathrm{kPa}$ and $671 \mathrm{kPa}$ respectively, and the average compressive strength is $672.9 \mathrm{kPa}$. When the cement admixture quantity is $10 \%$, the unconfined compressive strength of stabilized slime samples is $1218.3 \mathrm{kPa}$, $1013.9 \mathrm{kPa}$ and $819.4 \mathrm{kPa}$ respectively, and the average compressive strength is 1017.2 $\mathrm{kPa}$. When the cement admixed is $12 \%$, the unconfined compressive strength of solidified slime samples is $1264.5 \mathrm{kPa}, 1303.1 \mathrm{kPa}$ and $1220.1 \mathrm{kPa}$ respectively, and the average compressive strength is $1262.6 \mathrm{kPa}$.

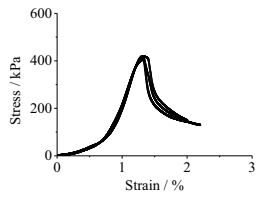

(a) Cement content of $6 \%$, curing age of 7 days.

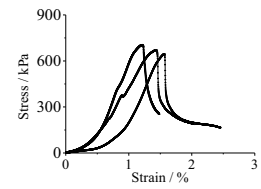

(b) Cement content of $8 \%$, curing age of 7 days.

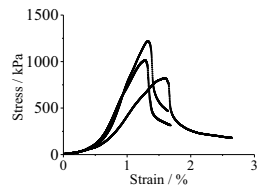

(c) Cement content of $10 \%$, curing age of 7 days.

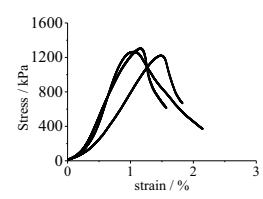

(d) Cement content of $12 \%$, curing age of 7 days.

Figure 1. Stress-strain curves of cement-solidified slime (Curing age $=7$ days) .

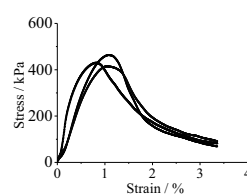

(a) Cement content of $6 \%$, curing age of 14 days.

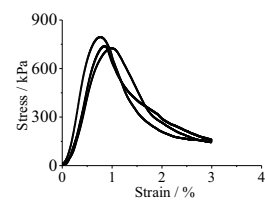

(b) Cement content of $8 \%$, curing age of 14 days.

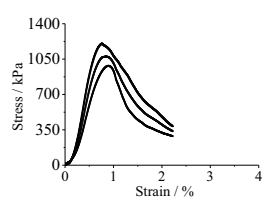

(c) Cement content of $10 \%$, curing age of 14 days.

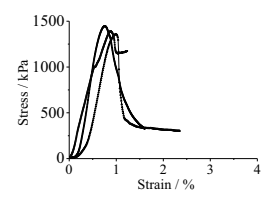

(d) Cement content of $12 \%$, curing age of 14 days.

Figure 2. Stress-strain curves of cement-solidified slime (Curing age $=14$ days).

At curing period of 14 days, the axial stress of solidified slime specimens with cement admixed amount of $6 \%, 8 \%, 10 \%$ and $12 \%$ increases with the increase of strain 
until to the peak, and then gradually decreases with the increase of strain. The stressstrain curves of cement-solidified tailings samples show brittle failure under unconfined conditions. When the cement admixed amount is $6 \%$, the unconfined compressive strength of cement-solidified slime samples is $463.3 \mathrm{kPa}, 429.8 \mathrm{kPa}$ and $414.3 \mathrm{kPa}$ respectively, and the average compressive strength is $435.8 \mathrm{kPa}$. When the cement admixed amount is $8 \%$, the unconfined compressive strength of solidified slime samples is $726 \mathrm{kPa}, 738.8 \mathrm{kPa}$ and $794.5 \mathrm{kPa}$ respectively, and the average compressive strength is $672.9 \mathrm{kPa}$. When the cement admixed amount is $10 \%$, the unconfined compressive strength of stabilized slime samples is $983 \mathrm{kPa}, 1202.9 \mathrm{kPa}$ and $1074.7 \mathrm{kPa}$ respectively, and the average compressive strength is $1086.9 \mathrm{kPa}$. When the cement admixed amount is $12 \%$, the unconfined compressive strength of solidified slime samples is $1445.6 \mathrm{kPa}, 1358.6 \mathrm{kPa}$ and $1391.3 \mathrm{kPa}$ respectively, and the average compressive strength is $1398.5 \mathrm{kPa}$.

At curing period of 28 days, the axial stress of solidified slime specimens with cement admixed amount of $6 \%, 8 \%, 10 \%$ and $12 \%$ increases with the increase of strain until to the peak, and then gradually decreases with the increase of strain. When the cement admixed amount is $6 \%$, the unconfined compressive strength of solidified slime samples is $483.7 \mathrm{kPa}, 492.5 \mathrm{kPa}$ and $483.7 \mathrm{kPa}$ respectively, and the average compressive strength is $486.6 \mathrm{kPa}$. When the cement admixed amount is $8 \%$, the unconfined compressive strength of solidified slime samples is $726.0 \mathrm{kPa}, 868.1 \mathrm{kPa}$ and $792.4 \mathrm{kPa}$ respectively, and the average compressive strength is $795.5 \mathrm{kPa}$. When the cement admixed amount is $10 \%$, the unconfined compressive strength of solidified slime samples is $1098.8 \mathrm{kPa}, 1316.5 \mathrm{kPa}$ and $1303.7 \mathrm{kPa}$ respectively, and the average compressive strength is $1239.7 \mathrm{kPa}$. When the cement admixed amount is $12 \%$, the unconfined compressive strength of solidified slime samples is $1696.1 \mathrm{kPa}, 1808.6 \mathrm{kPa}$ and $1593.9 \mathrm{kPa}$ respectively, and the average compressive strength is $1699.7 \mathrm{kPa}$.

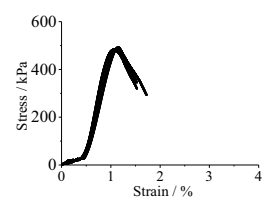

(a) Cement content of $6 \%$, curing period of 28 days.

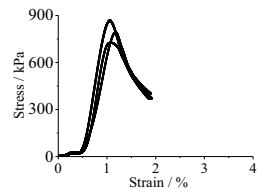

(b) Cement content of $8 \%$, curing period of 28 days.

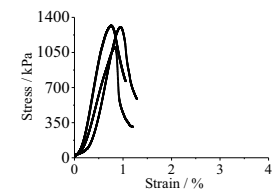

(c) Cement content of $10 \%$, curing period of 28 days.

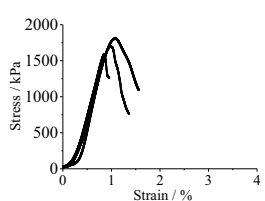

(d) Cement content of $12 \%$, curing period of 28 days.

Figure 3. Stress-strain curves of cement-solidified slime (Curing age $=28$ days).

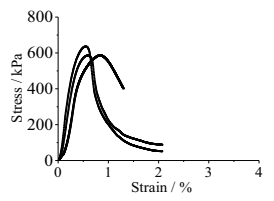

(a) Cement content of $6 \%$, curing age of 90 days.

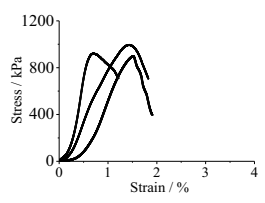

(b) Cement content of $8 \%$, curing age of 90 days.

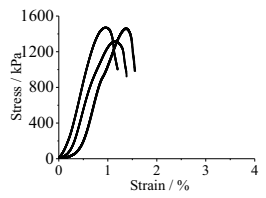

(c) Cement content of $10 \%$, curing age of 90 days.

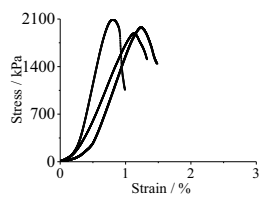

(d) Cement content of $12 \%$, curing age of 90 days.

Figure 4. Stress-strain curves of cement-solidified slime (Curing age $=90$ days).

At curing age of 90 days, the axial stress of solidified slime samples with cement admixed amount of $6 \%, 8 \%, 10 \%$ and $12 \%$ increases with the increase of strain until to 
the peak, and then gradually decreases with the increase of strain. The stress-strain curves of cement-solidified tailings samples show brittle failure under unconfined conditions. When the cement admixed amount is $6 \%$, the unconfined compressive strength of solidified slime samples is $586 \mathrm{kPa}, 585.8 \mathrm{kPa}$ and $635.6 \mathrm{kPa}$ respectively, and the average compressive strength is $602.5 \mathrm{kPa}$. When the cement content is $8 \%$, the unconfined compressive strength of solidified slime samples is $897.7 \mathrm{kPa}, 920.4 \mathrm{kPa}$ and $994.7 \mathrm{kPa}$ respectively, and the average compressive strength is $937.6 \mathrm{kPa}$. When the cement admixed amount is $10 \%$, the unconfined compressive strength of cement stabilized slime samples is $1458.4 \mathrm{kPa}, 1468.2 \mathrm{kPa}$ and $1312.8 \mathrm{kPa}$ respectively, and the average compressive strength is $1413.1 \mathrm{kPa}$. When the cement amount admixed is $12 \%$, the unconfined compressive strength of solidified slime samples is $1979.4 \mathrm{kPa}$, $2088.9 \mathrm{kPa}$ and $1887.1 \mathrm{kPa}$ respectively, and the average compressive strength is $1985.2 \mathrm{kPa}$.

\subsection{Influence of Cement Content on UCS of Solidified Slime}

Figure 5 demonstrates the curves of unconfined compressive strength of solidified slime changing with cement content. According to the curves, under the four curing ages of 7 days, 14 days, 28 days and 90 days, the failure strength of solidified tailings slime increases with the increase of cement admixed amount. Under the same conditions, the higher the cement content, the greater the failure strength of solidified tailings slime. It can also be seen from the figure that when the cement content increases from $6 \%$ to $12 \%$, the unconfined compressive strength of the solidified slime specimens increases with the increase of the curing agent content.

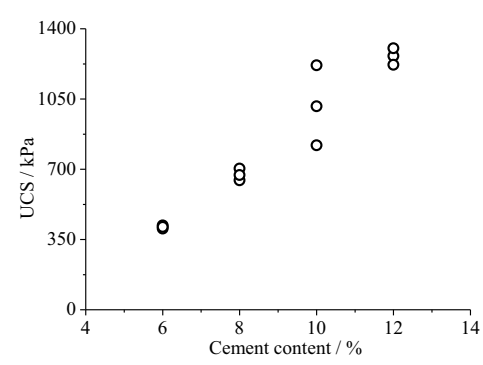

(a) Curing age of 7 days.

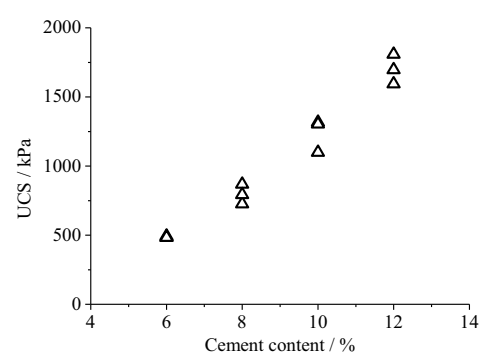

(c) Curing age of 28 days.

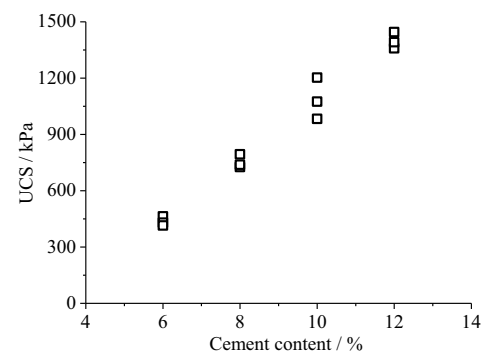

(b) Curing age of 14 days.

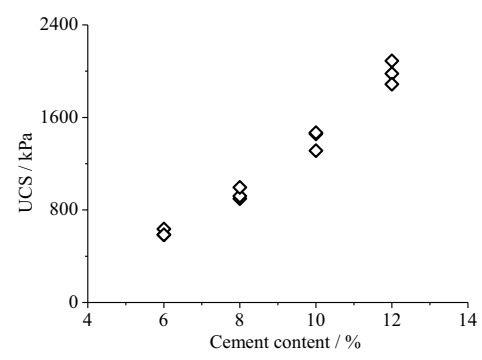

(d) Curing age of 90 days.

Figure 5. Curves of UCS of solidified slime changing with cement content. 
Taking figure 5(b) as an example, when the curing age of cement-solidified tailings slime samples is 28 days, the unconfined compressive strength is $486.6 \mathrm{kPa}$ when the cement content is $6.0 \%$, and that is $795.5 \mathrm{kPa}$ when the cement content is $8.0 \%$, which increases by 1.6 times. When the cement content is $10.0 \%$, the unconfined compressive strength of solidified slime is $1239.7 \mathrm{kPa}$, which increases by 1.6 times. When the cement content is $12.0 \%$, the unconfined compressive strength of solidified slime is $1699.7 \mathrm{kPa}$, which increases by 1.37 times. To sum up, within the test range, the unconfined compressive strength of solidified slime increases with the increase of cement admixed amount.

The increase in strength of cement-solidified slime is mainly due to hydration reaction of cement and pozzolanic reaction between calcium hydroxide (a product of hydration reaction) and silicon ions in tailings. After adding cement to the soil, the main clinker minerals in cement, such as tricalcium silicate, dicalcium silicate, tricalcium aluminate and gypsum, react with water to produce calcium silicate hydrate, calcium aluminate hydrate, calcium alumino-ferrite hydrate and other products. At the same time, calcium hydroxide, a product of cement hydration reaction, further undergoes pozzolanic reaction with silica in clay, generating more hydration products. The hydration products crystallize to form bonds between clusters and particles, and the bonds between particles make the cement-soil material form significant cohesive force. However, the hydration reaction of cement is fast and mainly occurs in the pores between particles, so that the soil particles and aggregates in the soil form a highstrength closed structure. In contrast, the reaction of calcium hydroxide produced by hydration with silica and alumina in clay mainly occurs on the surface of clay minerals, so the pozzolanic reaction products mainly make clay particles bond with each other. Gypsum in cement is also a factor that makes the strength of reinforced soil increase slowly. Calcium sulfate reacts with water to form hydrate, and the flocculent structure formed by hydrate can significantly increase the content of calcium ions in soil, and change the microstructure of cement-solidified slime. Meanwhile, the mineral formed by gypsum crystallization has certain expansibility, which can improve the compactness of soil.

\subsection{Influence of Curing Age on UCS of Solidified Slime}

In the process of slime disposal and recycling, cement solidified material is often used as bearing layer or backfill in the engineering, and the development law of its strength and deformation with time is a common concern in the engineering sector, while the growth law of strength of different types of solidified soil with time is also different. Especially for tailings slurry, its strength changes with curing age need to be revealed through experimental study. In view of this, the change rules of strength of the solidified tailings slurry with curing age under different curing ages were studied herein, and the test results are shown in the figure 6 below.

Figure 6 exhibits the curves of unconfined compressive strength of solidified slime changing with curing age. According to the curves, the strength of cement-solidified slime increases with the increase of curing period. Under the same conditions, the longer the curing age, the higher the strength. Taking figure 6(a) as an example, the unconfined compressive strength of solidified slime is $412.3 \mathrm{kPa}$ when the maintenance age is 7 days; $435.9 \mathrm{kPa}$ when the curing time is 14 days, which increases by 1.06 times; $486.6 \mathrm{kPa}$ when the curing period is 28 days, which increases by 1.12 times; and $602.4 \mathrm{kPa}$ when the curing time is 90 days, which increases by 1.25 times. The main 
reasons why the strength of solidified slime increases with the increase of curing age are as follows: with the increase of maintenance age, the content of hydration reaction products in soil gradually increases, while the hydration products gradually harden with the increase of curing period, and the cementation between particles is strengthened, which increases the resistance of the solidified slime to shear deformation, showing the characteristics that the strength increases with the increase of curing age at the macro level.

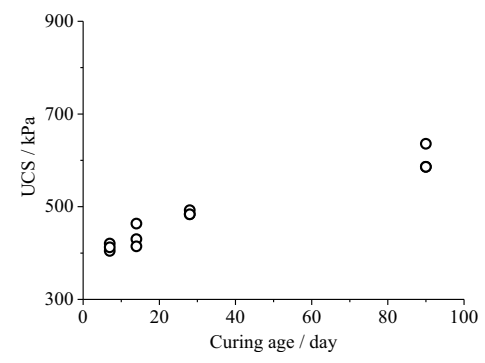

(a) Cement content of $6 \%$.

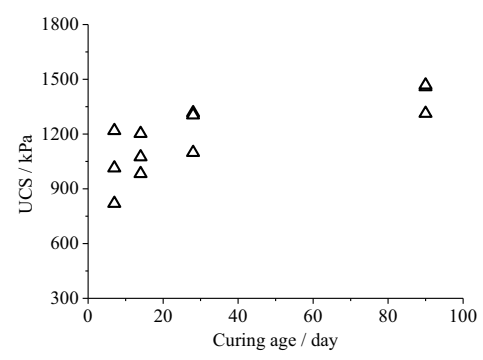

(c) Cement content of $10 \%$.

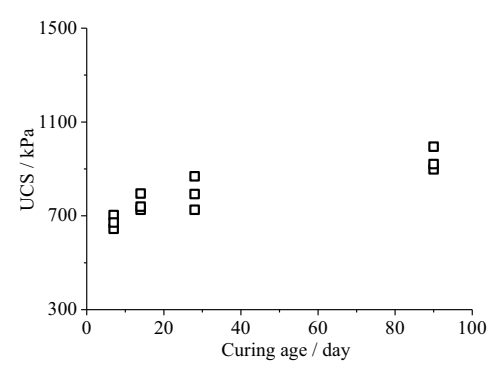

(b) Cement content of $8 \%$.

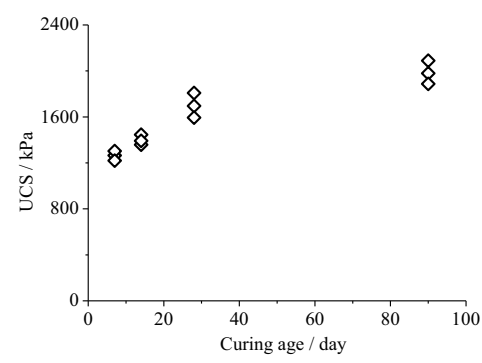

(d) Cement content of $12 \%$.

Figure 6. Curves of UCS of solidified slime changing with curing age.

\section{Conclusions}

Experimental study was conducted on the strength characteristics of cement-solidified slime with bauxite in order to explore the effectiveness of solidification technology in processing bauxite slime. The impact of cement contents and curing ages on the compressive strength of cement-solidified slime were investigated based on the experiments carried out in this research, some meaningful conclusions can be achieved as follows:

(1) Solidified slime with cement content greater than $6 \%$ presents brittle failure characteristics during shearing. The axial stress increases with the increase of strain firstly, and then decreases rapidly with the increase of strain after reaching the peak, and the failure strain is all less than $2 \%$.

(2) The shear strength of solidified slime is related to cement admix content, curing time, and among others. Within the test range, the higher the cement content and the longer the curing age, the greater the compressive strength of solidified slime. 


\section{Acknowledgments}

This study has been subsidize by the Central Public-interest Scientific Institution Basal Research Fund grant funded by the Chinese government (NO. Y32002, NO. Y32003, NO. Y921011). This study has also been supported by a grant from Technology Demonstration Project of China's Ministry of Water Resources (SF-202109) and from Transportation Science and Technology Project of Jiangsu Province. The authors also want to thank those technicians working for the State Key Lab of Hydrology-Water Resources and Hydraulic Engineering and Department of Civil Engineering, Nanjing Hydraulic Research Institute.

\section{References}

[1] Du ChX, Peng ZhB, Yang ChD, Cen LQ and Chen A. Experimental study of solidification technology of the bauxite mine slime. Journal of Engineering Geology. 2006 Jan; 1:117-21.

[2] Chen JB. Slime Hazard and countermeasure. China's Manganese Industry. 1998; 2: 3-5.

[3] Ouyang $\mathrm{ChH}$, Zhou ChCh, Han R, Zhang NN. Application of filter aid in dewatering of bauxite flotation tailings. Metal Mine. 2016 Jan; 45(1): 97-9.

[4] Li YT and Zhang YL. Practices of efficient high frequency dewatering screen technology in dry discharge of tailings. Gold. 2016 May; 37(5): 66-70.

[5] Zhan LT, Zhang P, Zhan XJ and Lin WA. Experimental study on inhibition effect of chemical conditioning on low permeability sewage sludge layer under conditions of vacuum preloading. Journal of Southeast University(Natural Science Edition). 2016 Nov; 46(s1): 7-13.

[6] Wang TH, Chen JH and Huang ZhY. Experimental study on pressure filtration dewatering of tailings material. Gold Science and Technology. 2018 Jun; 26(3): 379-86.

[7] Zhang YK and Ren XQ. Analysis of tailings dry drainage treatment process. Hebei Metallurgy. 2020 Apr; 4: 80-2.

[8] Liang GH and Hong XP. The successful application and reform of the technology of pressure filtration and dry heaping of tail in Panshanlou gold mine. Gold. 2003 Dec; 24(12): 47-9.

[9] Liu QY, Li ChY and Wang B. Application of dry deposition technology of pressure tailings in Jinling iron mine. Metal Mine. 2006 Aug; 36(8): 479-81.

[10] Qi MCh, Qian ShH, Wu H, Li BJ, Shi G and Pan M. Dewatering test of low concentration and fine tailings in Zhangzhuang iron mine. Modern Mining. 2019 Dec; 35(12): 148-51.

[11] Sun ZhF, Song LM, Zhu L and Tang ShY. Exploration and practice of high concentration emission technology of deep cone thickener. Mining Engineering. 2019 Jan; 17(1): 24-6.

[12] Zhang NN, Zhou ChCh, OuYang $\mathrm{ChH}$ and Han R. Experimental study on dewatering of the flotation tailings of bauxite in Henan. Multipurpose Utilization of Mineral Resources. 2016 Apr; 2(2): 93-6. 